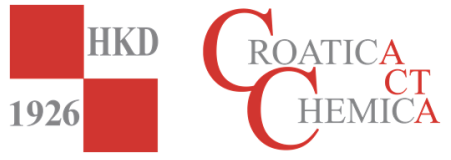

\title{
UV Photoelectron Spectroscopy and Outer Valence Electronic Structure of Dihalobenzenes ${ }^{\dagger}$
}

\author{
Igor Novak,,${ }^{\mathrm{a}, *}$ Leo Klasinc, ${ }^{\mathrm{b}, \mathrm{e}}$ Boris Šket, ${ }^{\mathrm{c}}$ Delano P. Chong, ${ }^{\mathrm{d}}$ and Sean P. McGlynn ${ }^{\mathrm{e}}$ \\ ${ }^{a}$ Charles Sturt University, $P O B$ 883, Orange NSW 2800, Australia \\ ${ }^{\mathrm{b}}$ Ruđer Bošković Institute, Bijenička cesta 54, HR-10000 Zagreb, Croatia \\ ${ }^{\mathrm{c}}$ University of Ljubljana, SI-1000 Ljubljana, Slovenia \\ ${ }^{\mathrm{d}}$ University of British Columbia, Vancouver, B.C. Canada V6T $1 Z 1$ \\ ${ }^{\mathrm{e}}$ Louisiana State University, Baton Rouge LA 70803, USA \\ RECEIVED FEBRUARY 27, 2014; REVISED APRIL 26, 2014; ACCEPTED MAY 9, 2014
}

\begin{abstract}
The electronic structures of nine dihalobenzenes $\left(\mathrm{C}_{6} \mathrm{H}_{4} \mathrm{FX} ; \mathrm{X}=\mathrm{Cl}, \mathrm{Br}, \mathrm{I}\right)$ have been studied by UV photoelectron spectroscopy (UPS) and assigned by comparison with the reported spectra of monohalobenzenes $\left(\mathrm{C}_{6} \mathrm{H}_{5} \mathrm{X} ; \mathrm{X}=\mathrm{Cl}, \mathrm{Br}, \mathrm{I}\right)$. and quantum chemical calculations. Our results show that the fluorine substituent modifies energies of $\pi$ - and halogen lone pair orbitals to a significant degree depending on its location (topology). We also demonstrate that the inductive effect of fluorine atom on the benzene ring can be readily observed and interpreted.
\end{abstract}

Keywords: halobenzenes, inductive effect, resonance effect

\section{INTRODUCTION}

In their recent work Antal et al. considered the influence of through-bond and through-space interactions on the shape of molecular electron density. ${ }^{1}$ The authors used theoretical method of shape analysis to provide quantitative measure of through-bond (TB) and through-space (TS) effects. Because of our long standing interest in the analysis and systematization of halogen substituent interactions in halobenzenes, we provide in this note some experimental results which can be useful for assessing the validity of theoretical concepts attached to TB and TS effects. We used accurate vertical ionization energies (which are good approximations of orbital energies) obtained from UV photoelectron spectroscopy (UPS) as the quantitative probe of TB and TS effects. Antal et al. ${ }^{1}$ selected substituted styrene derivatives as their test case. However, we use smaller dihalobenzenes, because they exhibit well resolved spectral bands thus allowing accurate ionization energies to be measured; this would not have been possible with larger styrene derivatives where the bands can be expected to overlap in the spectra. Furthermore, the unambiguous spectral assignments for our molecules can be readily obtained using the empirical arguments. These arguments can thus support any conclusions drawn from theoretical calculations.

\section{EXPERIMENTAL}

Samples of the compounds studied in this work were obtained from Sigma-Aldrich. The photoelectron spectra (Figures 1-9) were recorded on the Vacuum Generators UV-G3 spectrometer and calibrated with small amounts of Xe gas which was added to the sample flow. The spectral resolution in $\mathrm{HeI}$ spectra was $25 \mathrm{meV}$ when measured as FWHM of the $3 \mathrm{p}^{-1}{ }^{2} \mathrm{P}_{3 / 2} \mathrm{Ar}^{+} \leftarrow \mathrm{Ar}$ $\left({ }^{1} \mathrm{~S}_{0}\right)$ line. The vertical ionization energy values have been determined at the band maxima. All the samples were liquids and their spectra were recorded at room temperature. The measured spectra were reproducible and showed no signs of decomposition e.g. no sharp peaks corresponding to possible small molecules (decomposition products) were observed. The spectra were reproducible over long time intervals. The quantum chemical calculations were performed with Gaussian 09 program $^{2}$ and included full geometry optimization of neutral molecules using B3LYP functional, 6-31G* basis set on all atoms except iodine where Stuttgart effective core potentials was used. ${ }^{3}$ The vibrational analysis confirmed that the resulting geometry was the true minimum (no imaginary frequencies). Subsequently, the optimized DFT geometry was used as the input into the single point calculation using the outer-valence Green's function (OVGF)

\footnotetext{
$\dagger$ Dedicated to Dr. Mirjana Eckert-Maksić on the occasion of her $70^{\text {th }}$ birthday.

* Author to whom correspondence should be addressed. (E-mail: inovak@csu.edu.au)
} 


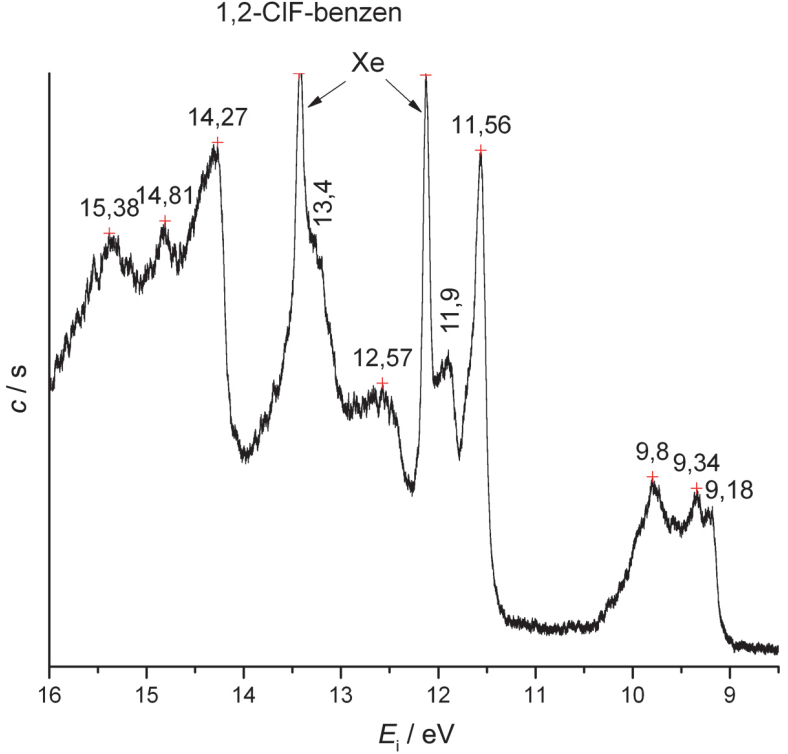

Figure 1. HeI spectrum of 2-chlorofluorobenzene.

method and the same basis sets. ${ }^{3}$ This method obviates the need for using Koopmans approximation and provides vertical ionization energies with typical deviation of $0.3-0.5 \mathrm{eV}$ (depending on the size of the basis set) from the experimental values.

\section{RESULTS AND DISCUSSION}

The photoelectron spectra are shown in Figures 1-9 and their assignments are summarized in Table 1. We shall briefly discuss the generic assignment of the spectra first and then focus on the substituent effects which can be discerned from the spectra.

It is well established that in the UPS spectra of monohalobenzenes the lowest ionization energies correspond to $\pi$-ionizations ( $\pi_{3}$ and $\pi_{2}$ orbitals) from HOMO

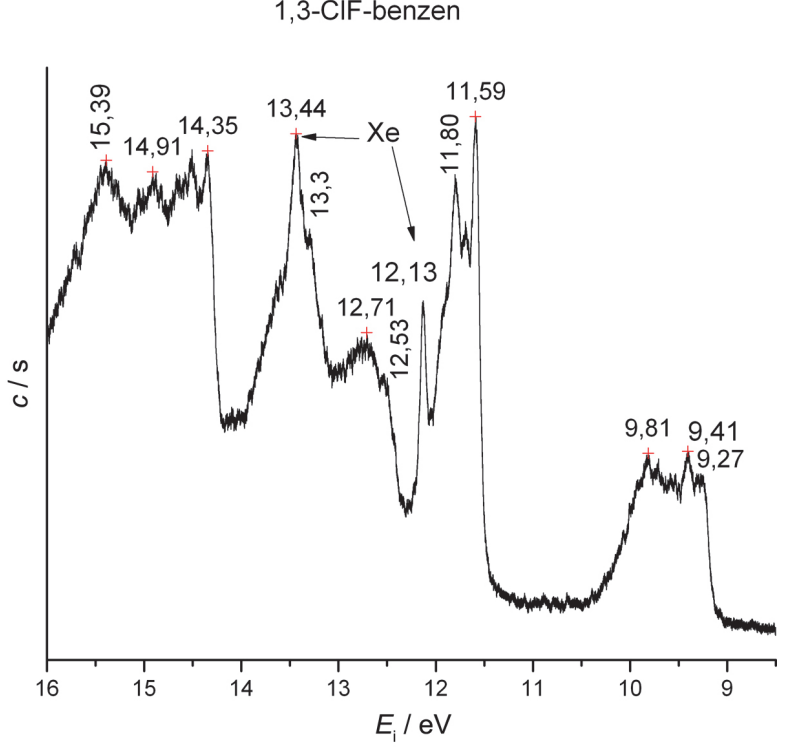

Figure 2. HeI spectrum of 3-chlorofluorobenzene.

and SHOMO orbitals. The next two bands at higher ionization energies correspond to halogen lone pairs of $\mathrm{Cl}, \mathrm{Br}$ or I. The fluorine lone pair ionizations are known to appear above the ionization energy of $16 \mathrm{eV} .^{4-7}$ This well established, empirical assignment (Scheme 1) allows us to readily assign our spectra as well (Table 1) and furthermore, it is also supported by the results of OVGF calculations (Table 1).

Before discussing inductive and resonance effects we recall several of their basic characteristics. The inductive effects operate via the network of $\sigma$-bonds and are therefore of predominantly TB type. The inductive effects are electrostatic in nature. The resonance effects depend on orbital overlap (often involving $\pi$-orbitals). Therefore the resonance effects involve predominantly (but not exclusively) TS interactions.

Table 1. Vertical ionization energies $\left(E_{\mathrm{i}} \pm 0.02 \mathrm{eV}\right)$, band assignments and results of OVGF calculations for the dihalobenzenes $\left(\mathrm{C}_{6} \mathrm{H}_{4} \mathrm{FX} ; \mathrm{X}=\mathrm{Cl}, \mathrm{Br}, \mathrm{I}\right)$; the values in brackets correspond to OVGF ionization energies

\begin{tabular}{|c|c|c|c|c|c|}
\hline Dihalobenzene & Band & $2-$ & $3-$ & $4-$ & MO \\
\hline \multirow{4}{*}{ chlorofluoro } & $X$ & $9.34(8.90)$ & $9.41(8.98)$ & $9.18(8.80)$ & $\pi_{3}$ \\
\hline & $A$ & $9.8(9.31)$ & $9.81(9.34)$ & $9.89(9.34)$ & $\pi_{2}$ \\
\hline & $B$ & $11.56(11.41)$ & $11.59(11.46)$ & $11.51(11.41)$ & $\mathrm{n}_{\mathrm{Cl}}$ \\
\hline & C & $11.9(11.81)$ & $11.86(11.74)$ & 11.75 (11.69) & $\mathrm{n}_{\mathrm{Cl}}$ \\
\hline \multirow{4}{*}{ bromofluoro } & $X$ & $9.23(8.82)$ & $9.18(8.90)$ & $9.13(8.72)$ & $\pi_{3}$ \\
\hline & $A$ & $9.69(9.26)$ & $9.74(9.30)$ & $9.89(9.55)$ & $\pi_{2}$ \\
\hline & $B$ & $10.79(10.62)$ & $10.82(10.68)$ & $10.78(10.64)$ & $\mathrm{n}_{\mathrm{Br}}$ \\
\hline & $C$ & $11.42(11.24)$ & $11.36(11.19)$ & $11.29(11.11)$ & $\mathrm{n}_{\mathrm{Br}}$ \\
\hline \multirow{4}{*}{ fluoroiodo } & $X$ & $8.85(8.65)$ & $8.95(8.73)$ & $8.82(8.64)$ & $\pi_{3}$ \\
\hline & $A$ & $9.50(9.34)$ & $9.55(9.43)$ & $9.88(9.58)$ & $\pi_{2}$ \\
\hline & $B$ & $9.95(9.48)$ & $10.02(9.60)$ & $9.88(9.62)$ & $\mathrm{n}_{\mathrm{I}}$ \\
\hline & C & $10.75(10.41)$ & $10.75(10.43)$ & $10.65(10.34)$ & $\mathrm{n}_{\mathrm{I}}$ \\
\hline
\end{tabular}




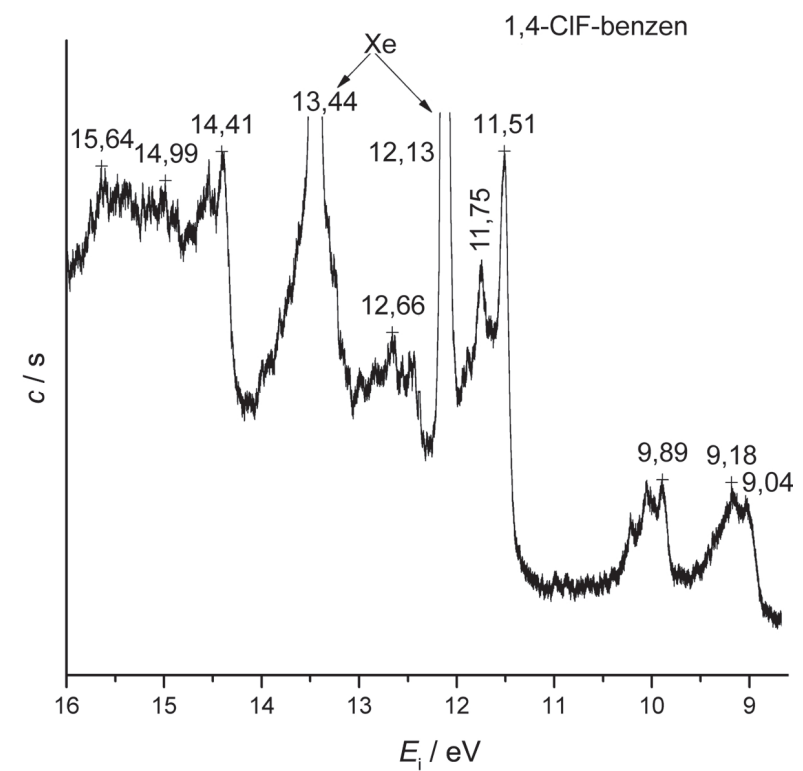

Figure 3. HeI spectrum of 4-chlorofluorobenzene.

The inspection of Table 2 shows several distinct trends regarding the influence of substituent topology on the electronic structure of dihalobenzenes. We also recall that the fluorine substituent acts on the aromatic system mostly in an inductive manner. We discuss next the orbital energy effects deduced from the spectra.

1. Energy splitting between $\pi$-orbital energies $\Delta \pi$ $\left(\Delta \pi=\pi_{3}-\pi_{2}\right)$ can be taken as an indicator of the $\pi$-electronic structure of the molecule. $\Delta \pi$ increases in para-substituted $\mathrm{C}_{6} \mathrm{H}_{4} \mathrm{FX}$ and decreases in meta- and ortho- isomers (all measured relative to the $\Delta \pi$ in the corresponding $\mathrm{C}_{6} \mathrm{H}_{5} \mathrm{X} ; \mathrm{X}=\mathrm{Cl}, \mathrm{Br}, \mathrm{I}$ ). The energy splitting between two halogen lone pairs in the $\mathrm{C}_{6} \mathrm{H}_{4} \mathrm{FX}$ molecules $\left(\Delta \mathrm{n}_{\mathrm{X}}\right)$ remains virtually unchanged in the ortho derivatives, but is

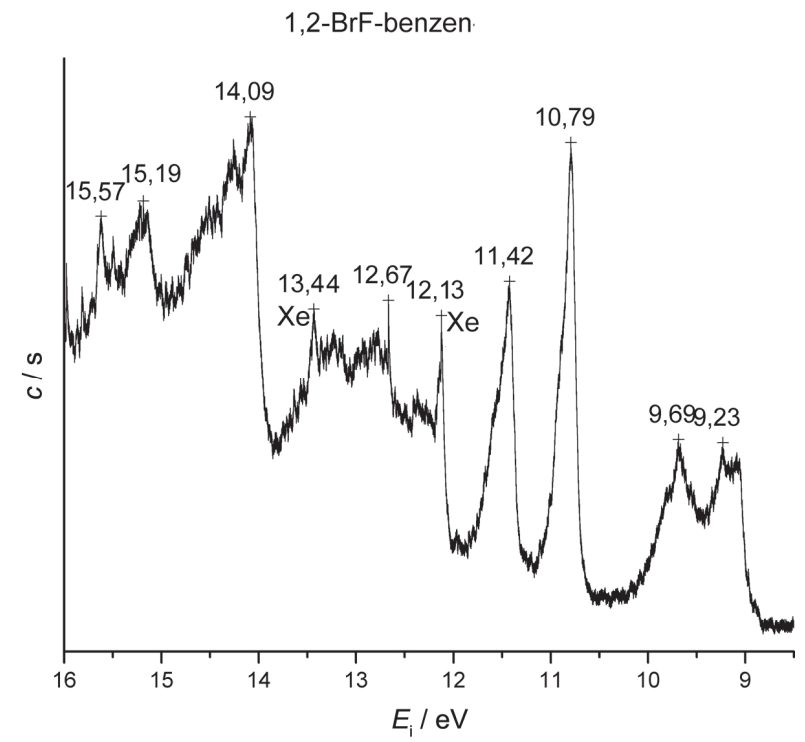

Figure 4. HeI spectrum of 2-bromofluorobenzene.
1,3-BrF-benzen

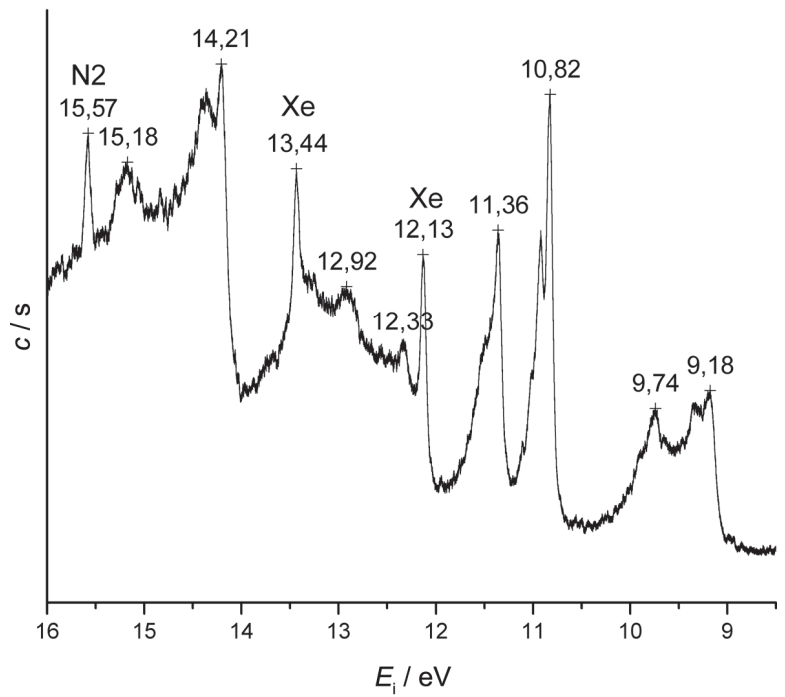

Figure 5. HeI spectrum of 3-bromofluorobenzene.

reduced in the meta- and para- isomers as shown in Table 2 (changes are measured again vs. $\Delta \mathrm{n}_{\mathrm{X}}$ in the corresponding $\mathrm{C}_{6} \mathrm{H}_{5} \mathrm{X} ; \mathrm{X}=\mathrm{Cl}, \mathrm{Br}, \mathrm{I}$ ).

2. In order to monitor the inductive effects we calculated average values of $\pi$ and $n_{\mathrm{X}}$ orbital ionization energies which we designate as $\langle\pi\rangle$ and $\left\langle\mathrm{n}_{\mathrm{X}}\right\rangle$, respectively. The results in Table 2 show the effect of fluorine on $<\pi>$; in $\mathrm{C}_{6} \mathrm{H}_{4} \mathrm{FX}<\pi>$ does not depend markedly on the position of the fluorine substituent (the variations are $<0.1 \mathrm{eV}$ ). The $\mathrm{C}_{6} \mathrm{H}_{4} \mathrm{FI}$ isomers are an exception. In these molecules the location of fluorine substituent has large influence on the $\langle\pi\rangle$ values; the strongest effect occurs in the ortho-isomer. Similar, limited influence of topology of fluorine substitution is evident for

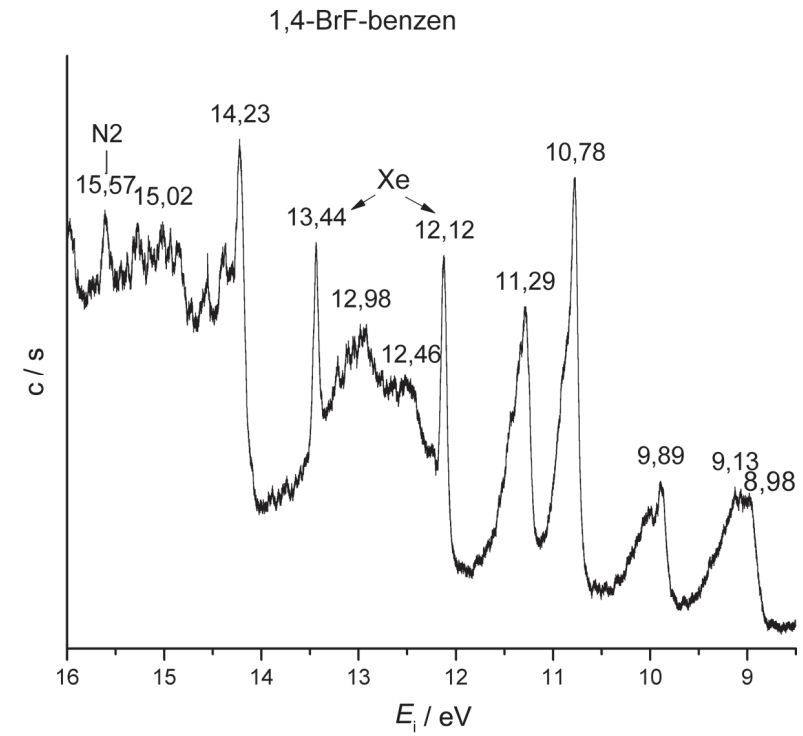

Figure 6. HeI spectrum of 4-bromofluorobenzene. 
Table 2. Changes in $\pi$-orbital $(\Delta \pi)$ and halogen lone pair $\left(\Delta \mathrm{n}_{\mathrm{X}}\right)$ energy splitting in $\mathrm{eV}$ and average energies of $\pi<\pi>$ and lone pair $<\mathrm{n}_{\mathrm{X}}>$ ionizations for the dihalobenzenes $\mathrm{C}_{6} \mathrm{H}_{4} \mathrm{FX}$ and monohalobenzenes $\mathrm{C}_{6} \mathrm{H}_{5} \mathrm{X} ;(\mathrm{X}=\mathrm{Cl}, \mathrm{Br}, \mathrm{I})$

\begin{tabular}{|c|c|c|c|c|c|}
\hline Dihalobenzene & Type & $2-$ & $3-$ & $4-$ & $\left(\mathrm{C}_{6} \mathrm{H}_{5} \mathrm{X} ; \mathrm{X}=\mathrm{Cl}, \mathrm{Br}, \mathrm{I}\right)$ \\
\hline \multirow{4}{*}{ chlorofluoro } & $\Delta \pi$ & 0.46 & 0.40 & 0.71 & 0.57 \\
\hline & $\Delta \mathrm{n}_{\mathrm{X}}$ & 0.34 & 0.21 & 0.24 & 0.36 \\
\hline & $<\pi>$ & 9.57 & 9.61 & 9.54 & 9.36 \\
\hline & $<\mathrm{n}_{\mathrm{Cl}}>$ & 11.73 & 11.70 & 11.63 & 11.49 \\
\hline \multirow{4}{*}{ bromofluoro } & $\Delta \pi$ & 0.46 & 0.56 & 0.76 & 0.64 \\
\hline & $\Delta \mathrm{n}_{\mathrm{X}}$ & 0.63 & 0.54 & 0.51 & 0.60 \\
\hline & $<\pi>$ & 9.46 & 9.46 & 9.51 & 9.31 \\
\hline & $<\mathrm{n}_{\mathrm{Br}}>$ & 11.11 & 11.09 & 11.04 & 10.92 \\
\hline \multirow{4}{*}{ fluoroiodo } & $\Delta \pi$ & 0.65 & 0.60 & 1.06 & 0.76 \\
\hline & $\Delta \mathrm{nx}$ & 0.80 & 0.73 & 0.77 & 0.83 \\
\hline & $<\pi>$ & 9.18 & 9.25 & 9.35 & 9.22 \\
\hline & $<\mathrm{n}_{1}>$ & 10.35 & 10.39 & 10.27 & 10.22 \\
\hline
\end{tabular}

halogen lone pairs $\left\langle\mathrm{n}_{\mathrm{X}}>\right.$. However, the $\mathrm{C}_{6} \mathrm{H}_{4} \mathrm{FI}$ isomers once again show stronger dependence of $<\mathrm{n}_{\mathrm{X}}>$ on the position of the fluorine atom.

The qualitative rationalization of these trends can be made with reference to the Scheme 1 as follows.

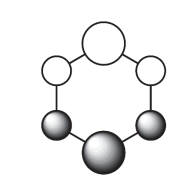

HOMO

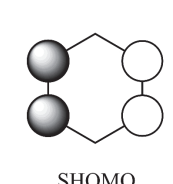

SHOMO

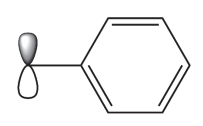<smiles>Oc1ccccc1</smiles>

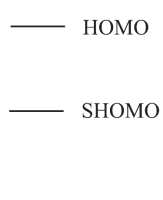

_ out-of-plane lone pair

orbital energy

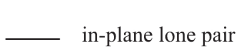

Scheme 1. $\pi$-orbitals and halogen lone pairs in benzenes

Ad 1. In para- $\mathrm{C}_{6} \mathrm{H}_{4} \mathrm{FX}$ isomers the electron rich fluorine atom is located close to the maximum of the electron density of the HOMO, but not of SHOMO $\pi$-orbital. This can be expected to destabilize the HOMO more than the SHOMO and thus increase the $\Delta \pi$ value. In the ortho- and meta- $\mathrm{C}_{6} \mathrm{H}_{4} \mathrm{FX}$ isomers the electron rich fluorine atom is situated close to the maximum of electron density of the SHOMO orbital; this orbital is therefore destabilized in preference to the HOMO which results in the reduced $\Delta \pi$ splitting. When considering the effect of topology of fluorine substituent on the $\mathrm{X}$ lone pairs in $\mathrm{C}_{6} \mathrm{H}_{4} \mathrm{FX}$ we need to recall that the fluorine substituent acts inductively via $\sigma$-bond framework (TB interaction) and mostly affects the in-plane $\left(\mathrm{n}_{\mathrm{X} \sigma}\right.$; $\sigma$-symmetry) halogen lone pair orbital rather than the out-of-plane ( $\mathrm{n}_{\mathrm{X} \pi} ; \pi$-symmetry) lone pair. In general, the

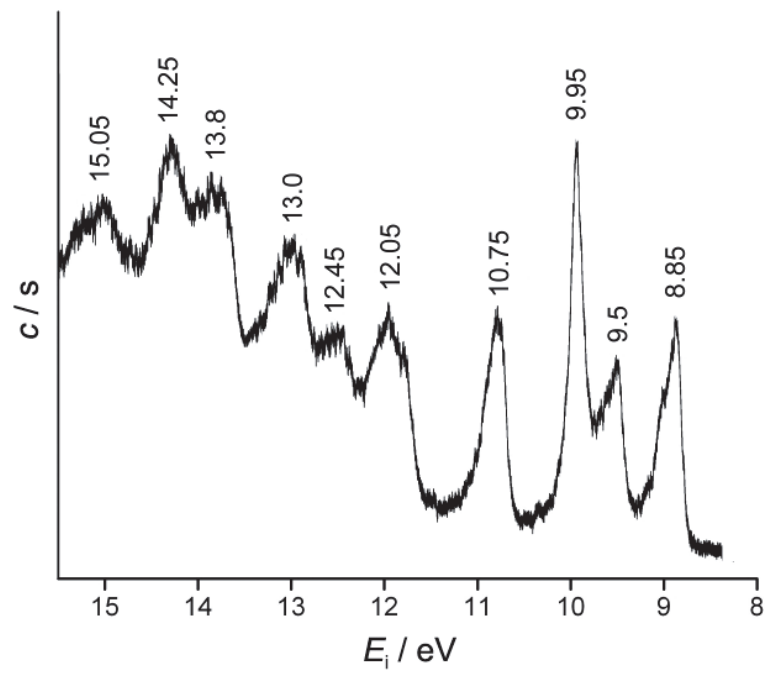

Figure 7. HeI spectrum of 2-fluoroiodobenzene.

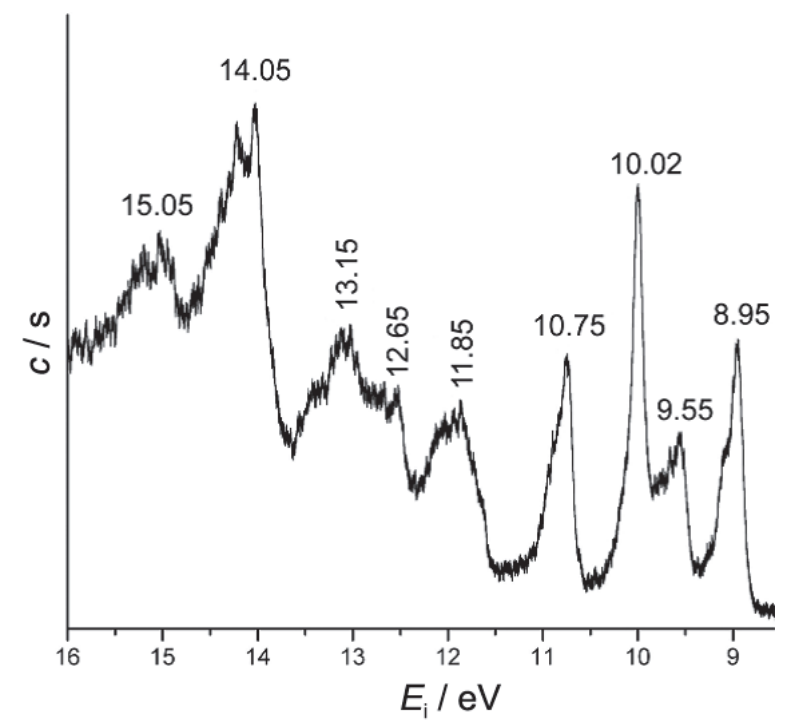

Figure 8. HeI spectrum of 3-fluoroiodobenzene 


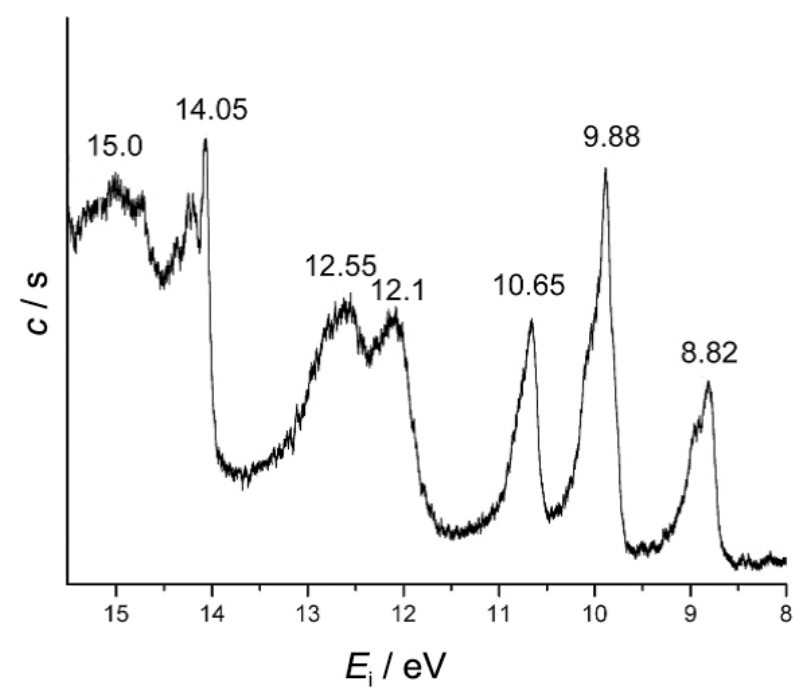

Figure 9. HeI spectrum of 4-fluoroiodobenzene.

$\mathrm{C}-\mathrm{F}$ bond dipole will tend to pull the halogen lone pair density away from X (in the direction of dipole's spatial orientation) thus stabilizing the corresponding $\mathrm{n}_{\mathrm{X} \sigma}$ and reducing $\Delta \mathrm{n}_{\mathrm{X}}$. In ortho- $\mathrm{C}_{6} \mathrm{H}_{4} \mathrm{FX}$ isomers we noticed two opposing effects. The $\mathrm{C}-\mathrm{F}$ bond dipole still pulls electron density away from $\mathrm{n}_{\mathrm{X} \sigma}$, stabilizing it. However, due to the spatial proximity between $\mathrm{X}$ halogen lone pair and fluorine lone pair in ortho- isomers we also have TS interaction between two fully occupied orbitals which leads to the destabilization of the lone pair with higher energy which is $n_{X \sigma}$. The net result is that there is no significant change in $\mathrm{n}_{\mathrm{X} \sigma}$ orbital energy and hence no change in $\Delta \mathrm{n}_{\mathrm{X}}$. On the other hand, in meta- and para$\mathrm{C}_{6} \mathrm{H}_{4} \mathrm{FX}$ isomers, there is no corresponding TS interaction and $\mathrm{C}-\mathrm{F}$ bond dipoles tend to pull the electron densities away from the in-plane $\mathrm{X}$ lone pairs thus stabilizing the $\mathrm{n}_{\mathrm{X} \sigma}$ orbital and reducing $\Delta \mathrm{n}_{\mathrm{X}}$.

Ad 2. The reason why the $<\pi>$ and $<\mathrm{n}_{\mathrm{X}}>$ values in $\mathrm{C}_{6} \mathrm{H}_{4} \mathrm{FI}$ are influenced by the positions of fluorine substituents more than in other dihalobenzene molecules is due to the large polarizability (and the low electronegativity) of iodine atom compared to the chlorine or bromine atoms.

\section{CONCLUSION}

We have shown that the inductive effect of fluorine on benzene ring can be described and interpreted in detail relying on experimental results. This is important because of the dominance of TB effects (of which the effect of fluorine on benzene ring is a case in point) as was suggested by Antal et al. ${ }^{1}$

Acknowledgements. Igor Novak thanks the Faculty of Science, Charles Sturt University for the financial support of this work through the CSU Competitive Grant OPA 4838. The authors also thank Dr Branka Kovač from the Ruđer Bošković Institute for measuring the UPS spectra.

\section{REFERENCES}

1. Z. Antal, P. L. Warburton, P. G. Mezey, Phys. Chem. Chem. Phys. 16 (2014) 918-932 and references therein.

2. Gaussian 09, Revision D1, M. J. Frisch, G. W. Trucks, H. B. Schlegel, G. E. Scuseria, M. A. Robb, J. R. Cheeseman, V. G. Zakrzewski, J. A. Montgomery, Jr., R. E. Stratmann, J. C. Burant, S. Dapprich, J. M. Millam, A.D. Daniels, K. N. Kudin, M. C. Strain, O. Farkas, J. Tomasi, V. Barone, M. Cossi, R. Cammi, B. Mennucci, C. Pomelli, C. Adamo, S. Clifford, J. Ochterski, G. A. Petersson, P. Y. Ayala, Q. Cui, K. Morokuma, D. K. Malick, A. D. Rabuck, K. Raghavachari, J. B. Foresman, J. Cioslowski, J. V. Ortiz, B. B. Stefanov, G. Liu, A. Liashenko, P. Piskorz, I. Komaromi, R. Gomperts, R. L. Martin, D. J. Fox, T. Keith, M. A. Al-Laham, C. Y. Peng, A. Nanayakkara, C. Gonzalez, M. Challacombe, P. M. W. Gill, B. Johnson, W. Chen, M. W. Wong, J. L. Andres, C. Gonzalez, M. Head-Gordon, E. S. Replogle, and J. A. Pople, Gaussian, Inc., Pittsburgh PA, 2009.

3. (a) W. Von Niessen, J. Schirmer, and L.S. Cederbaum, Comp. Phys. Rep. 1 (1984) 57-125. (b) U. Häussermann, M. Dolg, H. Stoll, and H. Preuss, Mol. Phys. 78 (1993) 1211-1244.

4. B. Ruščić, L. Klasinc, A. Wolf, and J. V. Knop, J. Phys. Chem. 85 (1981) 1486-1489.

5. T. Cvitaš and L. Klasinc, Croat. Chem. Acta 50 (1977) 291.

6. T. Cvitaš, H. Güsten, and L. Klasinc, J. Chem. Soc. Perkin 2 (1977) 962.

7. D. M. P. Holland, D. Edvardsson, L. Karlsson, R. Maripuu, K. Siegbahn, A. W. Potts, and W. Von Niessen, Chem. Phys. 253 (2000) 133. 